\title{
Radiologia em Odontopediatria Importância e Indicações
}

\author{
Márcla Reck Borges* \\ Icléo Farla e Souza** \\ Fernando Borba de Araújo**
}

\begin{abstract}
RESUMO
Ao fazermos o exame radiográfico em Odontopediatria devemos pesar o risco versus o benefício do exame já que a criança é mais suscetível aos efeitos danosos da radiação $X$. Assim, o exame radiográfico deve ser feito segundo as necessidades individuais do paciente.

As radiografias obtidas devem ter valor diagnóstico e para isso a técnica radiográfica a ser utilizada deve ser escolhida cuidadosamente. A proteção do paciente deve ser feita com aventais e colares de chumbo.
\end{abstract}

\begin{abstract}
SUMMARY
When a Dental Radiographic Survey is made in Pedodontics we have to ponder the risks versus benefits of the survey since children are more subject to radiation damage effects. This way, the radiographic examination must be made according to the specific necessities of the patient.

The radiographs obtained must have diagnostic value so then the thecnics to be used must be chosen carefully. The patient's protection must be made with lead aprons and collars.
\end{abstract}

\section{DESCRITORES}

Radiografia; Radiação; Dente Decíduo.

\section{INTRODUÇÃO}

A radiografia é um valioso recurso auxiliar de que dispomos para fazer um bom diagnóstico e plano de tratamento adequado. No entanto cada exposição traz um risco, principalmente no exame radiográfico em Odontopediatria já que a criança é mais sucetível aos efeitos danosos da radiação $(5,6,9,13,14)$ pois possui células que se reproduzem e crescem rapidamente em mui tas partes do corpo e a radiossensibilidade celular é diretamente proporcional à atividade mitótica e inversamente proporcional ao grau de diferenciação celular (4). Portanto, é impor-
*Aluna do Curso de Pós-Graduação em Odontopediatria - Nivel Especialização da FO-UFRGS.

**Professor Titular de Radiologia da FOUFRGS.

***Professor Adjunto de Odontopediatria da FO-UFRGS. 
tante estarmos cientes dos efeitos da radiação $X$ no organismo, usarmos de um bom critério para justificar o exame radiográfico e nos preocuparmos com a redução do número de repetições de radiografias e os métodos de proteção do paciente.

\section{EFEITOS BIOLÓGICOS DA RADIAÇÃO $X$}

Os efeitos danosos de altas doses de radiação $X$ são conhecidos há bastante tempo. No entanto, para baixas doses como as empregadas em radiografias dentais a magnitude do risco permanece incerta (13). Segundo o CDMIE (3), os principais riscos associados com baixas doses de radiação são o câncer, as mu tações e anomalias congênitas.

Efeitos Genéticos - São os efeitos biológicos ocasionados pela ação das radiações sobre os cromossomos (4). Os riscos de mutação por exposição às gônadas como resultado de radiografias dentais têm sido estimados em aproximadamente uma mutação em um milhão de nascimentos (3).

Câncer - Após a observação da ocorrência de um excesso de leucemia nos últimos 40 anos nos sobreviventes da bomba atômica japonesa, - câncer passou a ser considerado como o maior risco à população que recebe doses subletais de radiação (3). Houve então argumentação sobre a presença ou ausência de uma dose limiar, ou seja, uma dose abaixo da qual não haveria risco de indução ao câncer. Estudos têm mostrado que para a maioria dos tumores não há um provável limiar de dose.

Segundo Valachovic e Lurie (13), o odontopediatra deve estar atento para o problema do fracionamento de dose (o efeito da soma da exposição radiativa de muitas pequenas exposições em intervalos de tempo variados sobre o potencial carcinogênico daquela dose de radiação), pois a prática de repetidas exposições durante a infância e juventude pode ser considerada como fracionamento de uma dose de radiação moderada (maior que 60R).

Existem vários problemas na estimativa do câncer radiogênico como o fato de ser indistingüível de outros tipos de câncer, e do período de indução do tumor ser longo variando de 10 a 35 anos (13). Para a média de exames radiográficos dentais há uma indução de câncer para cada milhão de pessoas que tenham recebido algum exame radiográfico dental (3).

Estas são apenas estimativas de risco e não fatos estabelecidos. Não há provas dos efeitos danosos da radiação em doses comumente empregadas nos exames radiográficos dentais, no entanto, até o presente, não foi possível provar a ausência destes efeitos (3).

\section{NECESSIDADE DO EXAME RADIORÁFICO EM ODONTOPEDIATRIA}

Segundo Howa:d (5), desde que haja um risco potencial para a criança com cada exposião radiográfica deve-se pesar o benefício esperado da radiografia contra o risco e reavaliar a prática da rotina radiográfica baseada somente no tempo decorrido desde o último exame, idade da criança ou desenvolvimento dental. Assim, o exame radiográfico deve ter a probabilidade de afetar o diagnóstico e tratamento do problema que, se não tratado, trará um risco à saúde mai or do que o associado com a exposição radiográfica. Em vista disto, vários autores colocam que o exame radiográfico deve ser individualizado para cada paciente bassado nas suas prioridades clínicai e história do paciente $(1,2,5$, $10,13,14)$, sendo esta a maneira de determinar a necessidade, tipo e freqüência do exame radiológico.

\section{SITUAÇÕES CLÍNICAS COM INDICAÇÃO PARA O EXAME RADIOGRÁFICO}

Existem situações clínicas em que radiografias dentais são impor- tantes para uma avaliação completa do caso, onde o benefício supera o risco que são: anomalias de desenvolvimento e erupção, trauma, infecção, acompanhamento de trauma ou infecção, detecção de cáries, avaliação ortodóntica e do 3. molar.

Anomalias de Desenvolvimento e Erupção - Os dentes supranumerários e a ausência congêni ta de prémolares são as duas anomalias de desenvolvimento mais comuns em crianças $(10,13)$. Deve-se fazer o exame radiográfico em uma idade ótima para detectar estes problemas, ou seja, 6 a 8 anos de idade.

Howard sugere (5) o exame com 4 filmes (2 oclusais e 2 interproximais com filme número dois) para a detecção de anomalias em dentição decídua e mista. Valachovic e Lurie (13) recomendam o exame intra oral com 6 filmes (2 oclusais anteriores e 4 periapicais posteriores).

quando houver atraso de erupção de dentes, deve-se tirar uma radiografia até os 12 meses de atraso. A comparação da erupção do dente contra-lateral pode ser útil (11). Periapicais de caninos podem ser feitas se estes dentes não são palpáveis clinicamente aos 9 anos (10).

Trauma - Segundo vários autores $(5,11,13)$, é importante fazermos uma radiografia logo após a injúria traumática. Para Andreasen (11), a radiografia inicial é importante como um padrão de comparação para exames futuros. Faz-se inicialmente uma radiografia periapical da área e, se necessário, outras radiografias complementares.

Infecção - É importante conhecermos a extensão da lesão antes de fazermos o diagnóstico ou tratamento $(11,13)$. Para Valachovic e Lurie (13) uma radiografia periapical de região é suficiente para demonstrar sua natureza e extensão.

Acompanhamento de Trauma ou Infecção - Radiografias podem sermeios efetivos de acompanhar a resposta óssea à terapia após trauma ou infecção (13).

Detecção de Cáries - A freqüência do exame deve ser ditada pelas considerações de atividade de cárie, grau de espaçamento entre os 
dentes posteriores e exame clínico $(7,13)$.

$\mathrm{Na}$ dentição decídua, se a face proximal dos decíduos não pode ser visualizada e inspecionada tatilmente então a radiografia deve ser feita para determinar a presença de cáries interproximais (10).

Considerando o risco do paciente à cárie como critério $(7,10)$ para a tomada de radiografias, quando a criança for de alto risco à cárie (higiene oral pobre, deficiência de flúor, doença prolongada, dieta rica de carboidratos, família com pobre saúde dental e defeitos de desenvolvimento $e$ anormalidades genéticas) deve-se fazer radiografias interproximais tão logo os dentes decíduos posteriores estejam em contato. Se cáries interproximais são detectadas então radiografias de controle são indicadas periodicamente até a criança ser classificada como paciente de baixo risco à cárie.

$\mathrm{Na}$ criança de baixo risco à cárie (bos saúde, exposta a ótimos níveis de flúor, com boa higiene e dieta com poucas exposições de carboidratos retentivos entre as refeições) devem ser feitas radiografias interproximais se os espaços posteriores estiverem fechados. Se nenhuma evidência de cárie for encontrada, então devem ser feitas radiografias a cada 12 a 18 meses (11) se os dentes decíduos estiverem em contato ou acima de 24 meses se os dentes permanentes estiverem em contato. Se a criança de baixo risco entrar na categoria de alto risco, devem ser feitas radiografias interproximais com maior freqüência.

\section{Manutenção de Espaço, Movimento Dentário Menor e Avaliação Ortodóntica}

Filmes periapicais selecionados ou uma panorâmica podem ser necessários (5).

\section{Avaliação do 3.: Molar}

É indicada para estabelecer a presença, posição e morfologia e alguma patologia associada. Esta ava- liação deve ser feita entre as idades de 14 a 17 anos (5). Uma avaliação inicial pode ser feita com 4 filmes periapicais (14).

\section{REDUÇÃO DO NÚMERO DE REPETIÇÕES DE RADIOGRAFIAS}

Todas as repetições são lastimáveis pois adicionam radiação ao paciente. Segundo Silha (12), existem duas categorias principais:

- a inesperada ou que não podia ser prevista pelo dentista como anatomia não usual, fal ta de cooperação do paciente ou vômito.

- as que podem ser previstas pelo dentista ou que são resultado de técnica pobre como erro no posicionamento do filme (uma das maiores causas de repetições), movimento do aparelho ou do paciente, uso errado dos fatores de exposição, falta de cuidado no processamento e mistura de filmes de pacientes diferentes perdendo a identificação.

Apresentaremos, a seguir, alguns cuidados a serem seguidos para evitar a repetição da radiografia e para expor o paciente a menor quantidade de radiação possível.

Filme - Deve ter a maior sensibilidade possivel. Para isto, utilizamos filmes do tipo "D" ou mais rápidos $(1,2)$. Os filmes devem ser sempre tratados com cuidado. Não devem ser curvados antes ou após serem posicionados na boca para evitar distorção de imagem ou artefatos e não devem ser expostos à radiação secundária.

Técnica Radiográfica - Devemos utilizar todas as condições necessárias para proporcionar conforto à criança durante a tomada radiográfica evitando sua movimentação e conseqüente necessidade de repetição da técnica.

- A radiografia na criança deve ser feita no menor tempo possível.

- Para crianças pequenas podemos utilizar o filme infantil ou um filme número dois dobrado $(6,8)$.

- Quando a criança não permite utilizarmos a técnica convencional, podemos utilzar variações de téc- nica ou recursos auxiliares para que obtenhamos radiografias com valor diagnóstico como: uso de portafilmes, rolos de algodão, realização de radiografias periapicais com a criança de boca fechada (filme dobrado), uso de técnicas oclusal para radiografias posteriores.

Exposição e Processamento Segundo White (14), a média dos dentistas expõe seus pacientes a doses duas vezes maiores que o necessário. Isto é resultado de processamento ruim da radiografia exigindo maior tempo de exposição. A sobre exposião acompanhada de processamento ruim condicionam o paciente e pessoal do consultório à radiação desnecessária. Há falta de contraste e perda de detalhe resultando em perda de informação diagnóstica (1, $2,14)$. Para Silha $(10)$, quanto mais padronizado o procedimento radiográfico se tornar para todos os pacientes mais consistentes serão os resultados radiográficos obtidos.

Visualização da Imagem - A radiografia deve ser examinada em condições próprias (uso de negatoscópio e lupa) para obtermos o máximo de informação possível (2).

Educação Continuada - $\mathrm{O}$ operador deve reconhecer a causa de algum insucesso na imagem para que a técnica possa ser corrigida sem causar mais exposição ao paciente (14).

Proteção do Paciente - Devem ser usados o avental e o colar de chumbo para minimizar qualquer radiação desnecessária $(1,2)$.

\section{CONCLUSÕES}

1. Apesar de não termos provas dos efeitos maléficos de baixas doses de radiação, não podemos desconsiderar a possibilidade de ocorrência do câncer e problemas genéticos associados à exposição radiográfica odontológica.

2. Quando o exame radiográfico for feito baseando-se nas necessidades individuais da criança, o benefício deste exame irá superar o risco envolvido no procedimento. 
3. As radiografias obtidas devem ter valor diagnóstico e, para isto, deve ser cuidadosa a escolha da técnica radiográfica a ser utilizada e suas variantes bem como do tamanho do filme. Além disto, o exame da radiografia com o uso do negatoscópio e lupa proporcionarão o máximo de informação possível.

4. A proteção do paciente deve ser feita com aventais e colares de chumbo para minimizarmos os efeitos danosos da radiação $X$.

\section{REFERÊNCIAS BIBLIOGRÁFICAS}

1. COUNCIL ON DENTAL MATERIALS AND DEVIDES. Recommendations in radiographic practices - March 1978.J. Am. Dent. Assoc., 96:485-8, Marc. 1978.

2. COUNVIL ON DENTAL MATERIALS, INS TRUMENTS AND EQUIPMENT. Recommendations in radiographic practices, 1981. J. Am. Dent. Assoc., 103:103-4, July, 1981.

3. COUNCIL ON DENTAL MATERIALS, INSTRUMENTS AND EQUIPMENT. Biological effects of radiation from dental radiography.J. Am. Dent. Assoc., 105-275-81, Aug. 1982.

4. FREITAS, L. \& BECKER, L. Natureza e produção dos efeitos biológicos. In: FREITAS, A. et alii. Radiologia odontologica. São Paulo, Artes Médicas, 1984. Cap. 6, p.65-77.

5. HOWARD, H.E. Rethinking pedodontic radiology. Assoc. J. Dent. Child., 48(3):192-7, 1981.

6. ISSAO, M. \& GUEDES PINTO, A.C. Radiologia em odontopediatria. In: .Manual de odontopediatria. 5.ed. São Paulo, Artes Médicas, 1981. Cap. 3, p.23-37.

7. LEVINE, N. \& STONEMAN, D.W. Paedodontic radiology. Ont. Dent., 55(6):11-4, 1978.

8. MC DONALD, R.E. \& AVERY, D.R. Métodos radiográficos. In: Odontopediatria. 4.ed. St. Louis, Mosby, 1986, p.111-130.

9. MYERS, D.R.; WEGE, W.R. \& GILBERT, M.A. Radiation exposure during panoramic radiography in children. Oral Surg. Oral Med. Oral Pathol., 46(4):588-93, Oct. 1978.

10. NOWAK, Aal. et alii. Summary of the Conference on Radiation Exposure in Pediatric Dentistry. J. Am. Dent. Assoc., 103:426-8, Sept. 1981.

11. OPPENHEIM, M.N. Pedodontic radiography. Ny State Dent. J., 47(2):88-90, Feb. 1981.

12. SILHA, R.E. Methods for reducing patient exposure combined with KODAK Ektaspeed Dental X-Ray Film. Dent. Radiogr. Photogr., 54(4):80-7, Nov. 1981.

13. VALACHOVIC, R.W. \& LURIE, A.G. Riskbenefit considerations in pedodontic radiology. Pediatr. Dent., 2(2):128-46, Feb. 1980.

14. WHITE, S.C. Radiation safety for children. Int. Dent. J., 3(3)259-64, Sept. 1982. 